Archives de sciences sociales des religions

136 | octobre - décembre 2006

Les Archives... cinquante ans après

\title{
Les Archives et les judaïcités contemporaines
}

Témoignage

Doris Bensimon

\section{CpenEdition}

Journals

Édition électronique

URL : http://journals.openedition.org/assr/3817

DOI : 10.4000/assr.3817

ISSN : $1777-5825$

Éditeur

Éditions de l'EHESS

Édition imprimée

Date de publication : 1 décembre 2006

Pagination : 67-70

ISBN : 2-7132-2124-2

ISSN : 0335-5985

Référence électronique

Doris Bensimon, "Les Archives et les judaïcités contemporaines », Archives de sciences sociales des religions [En ligne], 136 | octobre - décembre 2006, mis en ligne le 02 janvier 2009, consulté le 23 avril 2019. URL : http://journals.openedition.org/assr/3817 ; DOI : 10.4000/assr.3817 


\section{Doris Bensimon}

\section{Les Archives et les judaïcités contemporaines}

\section{Témoignage}

En janvier 1963, j’ai été recrutée comme assistante de recherche au CNRS. Je préparais une thèse de doctorat d'État: mon projet de recherche était une enquête sur l'intégration des immigrants originaires d'Afrique du Nord en Israël. Raymond Aron était mon directeur de thèse et mon parrain au CNRS, qui m'avait accordée pendant trois années une mission en Israël. Chargée de mes nombreux questionnaires et d'autres documents, je suis rentrée en France fin décembre 1965. À Paris, je devais être affectée à un laboratoire de recherche et à une équipe. Raymond Aron et Georges Friedmann, que j'avais accompagné lors de ses séjours en Israël, ont demandé mon affectation au Centre d'études sociologiques (CES). J'y ai d'abord rencontré Jean Stoetzel, qui accepta la direction de ma thèse complémentaire sur l'intégration des Juifs originaires d'Afrique du Nord en France. Mes recherches concernaient des populations juives. Le judaïsme étant une religion, on a donc demandé à É. Poulat de m'accueillir au Groupe de sociologie des religions où j'arrivais avec un nouvel objet de recherche : les judaïcités contemporaines.

Au CES, 82, rue Cardinet, le GSR disposait d'un espace très restreint et lors de mes passages, je disposais d'un petit coin de la grande table du bureau. Je fis la connaissance des membres du GSR où Jacques Maitre me donna de précieux conseils en méthodologie.

En 1966, les Archives de Sociologie des Religions fêtaient leur dixième anniversaire. Dès mon arrivée, on me confia quelques livres. Je lisais le néerlandais, aussi, pendant plusieurs années, je fus chargée de la recension des ouvrages en cette langue consacrés à l'étude du christianisme aux Pays-Bas. Je traitais aussi d'autres livres en anglais ou en allemand. Les ouvrages à thème juif en français étaient peu nombreux jusqu'au milieu des années 1970. Avant mon arrivée au GSR, Jean Hadot en était le principal recenseur.

Je me rendis rapidement compte de l'importance des Archives de Sociologie des Religions dans les activités des membres du GSR. À cette époque, les chercheurs et leurs recensions s'intéressaient surtout au catholicisme, au protestantisme, aux 
sectes d'origine chrétienne. La première religion monothéiste, le judaïsme, n'était pas oubliée, mais rarement évoquée. Dans le deuxième numéro des ASR, un auteur israélien présenta les kibboutzim religieux ${ }^{1}$. Dix ans plus tard, parut dans les ASR un long article de Georges Levitte sur les mutations de la population juive en France ${ }^{2}$.

Ma présence au GSR suscitait des débats concernant une sociologie des judaïcités contemporaines. En décembre 1969, les ASR publièrent un long article intitulé «Le Groupe de sociologie des religions. Quinze ans de vie et de travail ». Parmi les «trois grands ensembles » des recherches figurait une « une ethnoreligion » : le judaïsme ${ }^{3}$.

Comme d'autres chercheurs du GSR, je faisais des enquêtes sur le terrain, d'abord avec des questionnaires, puis avec des méthodes qualitatives. Pendant l'été 1968 , le GSR déménagea au 22, rue d'Athènes. Ces nouveaux locaux, considérés comme une annexe du CES de la rue Cardinet, permettaient aux personnels du GSR de disposer de bureaux et d'une grande salle pour des réunions. Ce déménagement resserrait les liens entre les membres du GSR et favorisait les échanges et les discussions ainsi que la réalisation de nouveaux projets de recherche. Progressivement, j’ai formé une équipe intitulée "judaïcités contemporaines " avec des vacataires et des chercheurs non affectés au CNRS : cette équipe était intégrée au Groupe de sociologie des religions.

Dans mes enquêtes, je posais des questions sur les pratiques religieuses. Mais le judaïsme n'est pas seulement une religion et je m'intéressais aux populations juives d'origines diverses, à leurs migrations et à leur acculturation aux pays d'accueil. J'étudiais les différentes affirmations de l'identité juive.

Ma participation aux ASR, qui devinrent en 1973 les Archives des Sciences sociales des Religions (ASSR), se limitait à la recension d'ouvrages de plus en plus nombreux. Dans les années 1970, Yves Chevalier, membre de l'équipe "judaïcités contemporaines ", en préparation de sa thèse de doctorat sur l'antisémitisme, fournit de nombreuses contributions aux ASSR et au bulletin bibliographique. Un peu plus tard, Jacques Gutwirth, anthropologue, spécialiste des juifs hassidiques, rejoignit les recenseurs des ASSR et y publia des articles ${ }^{4}$. À la même période, Régine Azria devint secrétaire de rédaction des ASSR et je fus nommée membre du comité de lecture.

De « la firme Groupe + Archives de Sociologie des Religions » évoquée par Henri Desroche ( $c f$. ci-dessus l'article d'André Mary), je retiens surtout le

1. Gabovitch B., "Les kibboutzim d'inspiration religieuse ", ASR, 2, juillet-décembre 1956, p. 98-101.

2. Levitte G., "Vers une étude des mutations de la population juive en France ", ASR, 22, juillet-décembre 1966, p. 89-102.
3. ASR, 28, juillet-décembre 1969, p. 40-42.
4. ASSR, Tables signalétiques (1977-1981), 1984, p. 294. 
"Groupe " qui m’a accordé les moyens nécessaires pour la réalisation de recherches sur la judaïcité française. Je ne citerai ici que les plus importantes.

Je partageais mon bureau avec Françoise Lautman qui, alors, s'intéressait aux familles. Nous décidâmes de faire une enquête sur les mariages entre chrétiens et juifs. Des sociologues américains avaient déjà publié des ouvrages sur ce thème. En France, on n'y prêtait guère attention. Avec d'autres chercheurs intéressés par les mariages mixtes, nous avons réfléchi et discuté de ce fait de société. Par la suite, de nombreux chercheurs se sont engagés dans l'étude de la diversité des couples mixtes. Pourtant, le livre que nous avons écrit ${ }^{5}$ est encore aujourd'hui un classique de référence.

Dans les années soixante, les démographes de l'Institut du judaïsme contemporain de l'Université hébraïque de Jérusalem, demandaient aux communautés de la diaspora la réalisation d'enquêtes démographiques auprès des populations juives. En 1967, une équipe de l'INED a répondu à cet appel. Cette équipe a élaboré la méthodologie d'une enquête sociodémographique auprès des juifs de France. La mise en route fut difficile et les premiers résultats jugés insuffisants par la responsable de l'équipe de l'INED. Début 1973, Sergio Della Pergola, alors directeur associé de l'équipe des démographes de l'Institut du judaïsme contemporain de l'Université de Jérusalem, me demanda de reprendre cette recherche. J'ai présenté Sergio Della Pergola à Émile Poulat, qui nous donna son accord : le programme fut transféré de l'INED au CNRS. L'équipe des judaïcités contemporaines du GSR s'investit dans cette entreprise particulièrement difficile. Le dernier recensement de la population française comportant une question sur l'appartenance confessionnelle remonte à 1872. Dans la France laïque, cette question est un tabou. De plus, la mémoire des juifs de France est chargée des souvenirs de la persécution par l'État de Vichy et par les occupants allemands.

Cette enquête provoqua des vives réactions dans les milieux juifs, mais nous l'avons réalisée. L'ouvrage écrit avec Sergio Della Pergola est toujours le livre de référence ${ }^{6}$.

Dans les années 1980, sociologues, psychologues, historiens s'intéressaient à une nouvelle collecte de données : l'histoire orale. Avec une autre équipe, nous avons obtenu la RCP « Histoire orale des Juifs de France ». La judaïcité française est une mosaïque par ses origines, ses migrations, ses mémoires. Cette RCP a intéressé de nombreux chercheurs et doctorants. Nous nous réunissions régulièrement rue d'Athènes. Chaque participant à ces réunions présentait son approche

5. Bensimon D., Lautman F., Un mariage. Deux traditions; Chrétiens et Juifs, Bruxelles, Éditions de l'Université libre de Bruxelles, 1977, 284 p.

6. Bensimon D., Della Pergola S., La population juive de France: socio-démographie et identité, Jerusalem, The Institute of Contemporary Jewry, The Hebrew University/Paris, Centre national de la Recherche scientifique, 1984, 436 p. 
personnelle et le groupe dont il voulait enregistrer les témoignages. Joëlle Allouche-Benayoun, qui rejoindra par la suite le GSR, et moi-même, prîmes contact avec des Juifs d'Algérie : leurs récits de vie sont devenus un livre ${ }^{7}$.

En France, dans les années 1980-1990, les études juives ont connu un essor considérable. L'équipe "judaïcités contemporaines » a joué un rôle pionnier dans le développement de ces études qui, dans notre esprit, étaient une contribution à la connaissance de l'Autre. Les ASR et ASSR ont accepté la publication d'articles et de recensions de nombreux livres à thème juif. Ces Archives ont diffusé la connaissance de l'Autre, juif.

7. Allouche-Benayoun J., Bensimon D., Juifs d'Algérie hier et aujourd'hui. Mémoires et identités, Toulouse, Bibliothèque historique Privat, 1986, 290 p.; $2^{\mathrm{e}}$ édition complétée : Les Juifs d’Algérie. Mémoires et identités plurielles, Paris, Éd. Stavit, 1998, 433 p. 